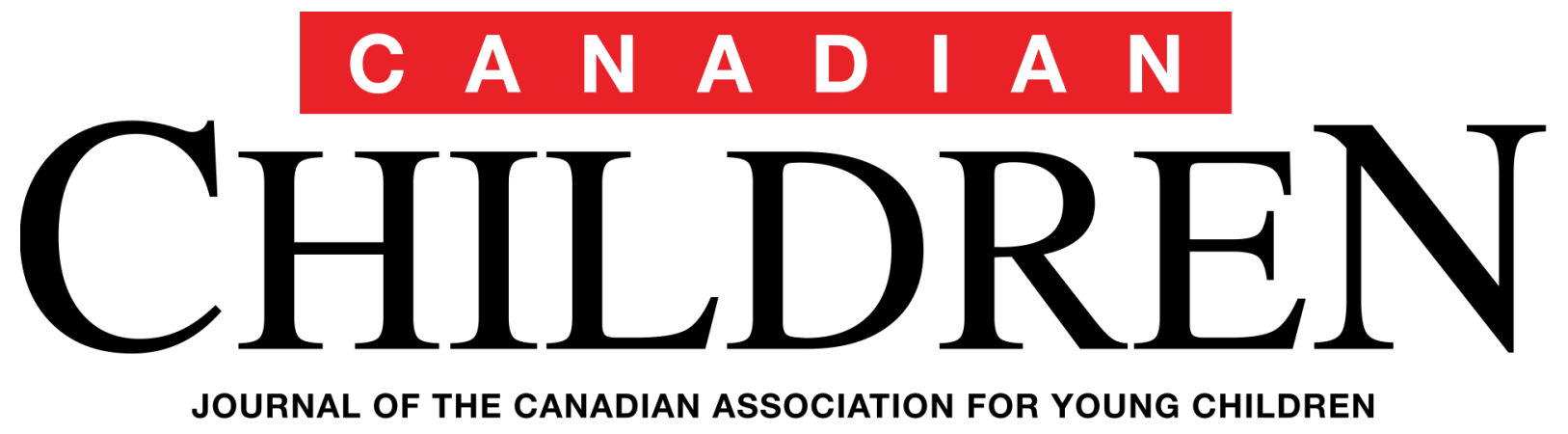

Winter 2014 / Hiver 2014

Vol. 39 No. 1

\title{
Neoliberal Fun and Happiness in Early Childhood Education
}

by Cristina D. Vintimilla

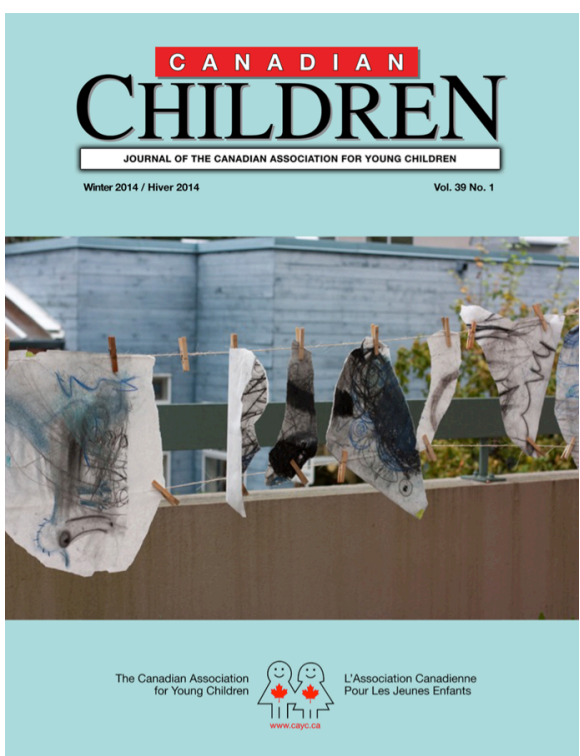

Editors:

Dr. Laurie Kocher, Douglas College, Coquitlam, British Columbia Dr. Veronica Pacini-Ketchabaw, University of Victoria, Victoria,

British Columbia

Guest Editor, Special Issue: Neoliberalism

Dr. Luigi Iannacci, Trent University, Peterborough, Ontario

Publications Chairperson:

Dr. Iris Berger, University of British Columbia, Vancouver, British Columbia

Cover Photo:

Dr. Sylvia Kind

(C) 1996: The Canadian Association for Young Children ISSN: 0833-7519

Author Guidelines: visit www.cayc.ca 


\title{
Canadian Children
}

JOURNAL OF THE CANADIAN ASSOCIATION FOR YOUNG CHILDREN

Volume 39 Number 12014 [page 79 to 87]

www.cayc.ca

\section{Neoliberal Fun and Happiness in Early Childhood Education}

\author{
by Cristina D. Vintimilla
}

\begin{abstract}
Author's Bio
Cristina Vintimilla became a pedagogista after studying at the University of Siena in Italy. She then received a $\mathrm{PhD}$ from the University of British Columbia. She is a faculty member in the School of Education and Childhood Studies at Capilano University and works closely with the Capilano Children's Centre as a pedagogista. Her research interests exist in the intersections between philosophy, the arts, and education.
\end{abstract}

\begin{abstract}
This paper considers neoliberalism, not only as a set of economic principles, but as a form of governance with political and social consequences. It argues for considering neoliberalism as that which produces subjects, ways of behaving, and organization of social and economic life. It then relates such consideration to the analysis of early childhood discourses on fun and happiness and how these discourses might sustain possibilities for the creation of neoliberal subjects.
\end{abstract}

\section{Why Bother With Neoliberalism in Early Childhood Education?}

Neoliberalism is a word one might hear repeated and used in different circumstances. It is also a word one might find difficult to define; it is vague and faintly accusatory. In some of the education and childhood studies university courses I teach, I have noticed that this word has special power: Once it is pronounced, once uttered out loud in the classroom, it can be followed by a tense, awkward moment of silence. Or, it can become a source of contestation. A colleague asked me once, "Why should one teach neoliberalism in an early childhood degree?" My students have asked: "Why should we bother studying this?"; "Why should we bother with neoliberalism when we have to learn how to teach children?"

These questions are the starting point for this article. Why bother with neoliberalism? This question is important because it invites inquiry into what neoliberalism is and what it does. 
More than the question of what neoliberalism is, the question of what it does provokes us to think about the concept in a more critical way. This approach entails seeing neoliberalism not simply as the set of economic principles that endorse a radical free market and policies that favour statism on the corporate model of business and profit in a globalized world, but as something more pervasive. Wendy Brown (2003) brings this point into focus:

"While these [economic] referents capture an important effect of neoliberalism, they also reduce neoliberalism to a bundle of economic policies with inadvertent political and social consequences" (p. 38).

Thus, when asking why we should bother with neoliberalism in early childhood education, it is necessary to recover and attend to neoliberalism's "inadvertent political and social consequences." To do so requires thinking about neoliberalism beyond economic effects, as a rationality, one which expands its normative ideology and values to other spheres of our lives through specific discourses and practices. Suddenly, neoliberalism is a more present concern than we may have thought. As one example, consider how popular culture has insinuated itself into early childhood curriculum and practices through images, artifacts, and literature.

Taking my students' questions from above as a starting point helps frame how I refer to neoliberalism in this article. I approach neoliberalism as a mode of governance-one that is not limited to the state, one that produces subjects, ways of behaving, and organization of social and economic life. As Brown (2003) writes, "the extension of economic rationality to formerly noneconomic domains and institutions reaches individual conduct, or, more precisely, prescribes the citizen-subject of a neoliberal order" (p. 42). In other words, we are called to think about neoliberalism, not only as a state's economic orientation, but as particular modes of subjectivity, and how one becomes (or may resist becoming) a neoliberal subject, especially through the project of education. How does neoliberalism, as a form of governance, define and structure the ways in which people conduct themselves (Foucault, 1994)? In university classrooms, for example, students assume the role of client or consumer, accumulating credits in the quest for a degree. Often students' interests are focused on one question: "What can I do to get an A in your class?" In this way students are the entrepreneurs of their own knowledge. This is no accidental development. It is the result of the pervasive insinuation of neoliberal discourse into the conduct of university life. The encroachment of "the businessmen of knowledge" into the university's constitution and operation is not new (see Kant's On the Conflict of the Faculties, 1798/1979); what is new is the very practice of learning as a mercantile matter. This is a neoliberal development (see Nussbaum's Not for Profit, 2010).

If we take up the question of neoliberalism in education, open it to interrogation as a condition of possibility for educators, children, and our institutions, we need to approach it as generative of questions - new questions which help us to see the early childhood education field 
for what it has become and may be becoming. Thus, in what follows, I engage with the following questions:

- In what ways is neoliberalism active in early childhood education?

- In what ways does it manifest, and through what discourses or apparent concerns?

- How may thinking about these questions expand into the ways we define and imagine the collective life (the life of relationships) in pedagogical contexts?

- How has neoliberalism come to shape the way educators relate to the question of what it means to live well with others?

As I have shown elsewhere (Vintimilla, 2012), these questions carry profound implications for who the early childhood educator is permitted to be. I take up these questions by attending closely to particular daily practices and discourses I have encountered in the different pedagogical contexts in which I move, both as a pedagogista and in my conversations with future early childhood educators. Specifically, I analyze the pervasiveness of the discourses of fun and happiness, and how they might work as a condition for the creation of neoliberal subjectivity.

\section{Fun as a Self-Evident Value in Pedagogical Contexts}

Often I ask first-year students why they have chosen to become an educator. I ask the question as a way to begin what Sarah Ahmed (2010) calls "the messiness of the experiential" (p. 574) in order to elicit, through discussing the work we share, the "drama of contingency, how we are touched by what goes near" (Ahmed, 2006, p. 124). Over the years I have noticed that a consistently high proportion of students answer with some version of "because we want to have fun experiences with children" or "because being with children is fun." I have been struck by how prominently "fun" appears everywhere in education in North America. Clearly, the discourse of fun does not live only among young students or only within the education field. I remember when I came to Canada years ago, I found it fascinating how, for the cashier at the grocery store, people I met at work, my friends, and even my professors at university, the word fun would be used so variously and with such apparent consensus. I recall being curious about how fun seemed to be an easy-touse term. I would ask the educators with whom I was working how their day had been and they would answer, "Oh, it was so much fun!" At the end of the day, over and over I would listen to parents asking children, "Did you have fun today?"

In early childhood settings, educators often arrange materials in different areas of the classroom for children to explore. I have noticed how children will stay in these areas, or with the

materials, until they are bored or they have decided the activity is not fun anymore. Then they are ready to jump to the next area or table. I suspect the presumption behind such classroom organization is that children can't be engaged for long periods of time. The consequence of this implication is that teachers provide for moments of fun as if that were a meaningful, or merely 
sufficient, way for children to spend their time. For, after all, one of the characteristics of a "good" teacher is that she can engage children.

It would be reductive to say that I am arguing for children and educators to not have fun; that is not the intention of this discussion. The intention is instead to notice, with the help of a critique of neoliberalism, how a discourse as "innocent" as the discourse of fun comes to reduce our important and diverse experiences in early childhood education and, further, how it participates in creating and managing subjectivities ${ }^{\mathrm{i}}$ (a matter to which I believe we turn far too little attention in the field).

Thus, I want to consider the connections between fun as a pervasive and self-evident value in pedagogical contexts and as a condition for the creation of neoliberal subjectivities. I contend that the concept of fun has evolved and developed into a central place in neoliberal societies, as one of the ideological vectors of subjective governance, even perhaps to the extent that we may consider fun "another tyrant molded by our culture and economy" (Bryant \& Forsyth, 2005, p. 197).

\section{The Neoliberal Discourse of Fun and the Management of Subjectivities}

Fun, and the expressions derived from it, lead to a "tendency to generalize experiences ... by declaring everything and everyone as an experience" (Wehr, 2004, p. 4, emphasis added). Expressions like "it was fun," "she is fun," "I'm having fun" confer meaning on experience without the need to ask how - indeed, by suggesting that the question is irrelevant. Additionally, the concept of fun as a neoliberal operant should be seen as a concept involved in the management and government of everyday life because it signifies a specific way of being in the world: taking life superficially and lightly; "no worries"; ostensibly "childish" playfulness; easy-going agreeability; not going too deeply into things; simplifying life. ${ }^{\text {ii }}$ Here, fun may be seen as an indicator of well-being and the successful conduct of a "good life."

Fun is thus a guarantor of the importance of experience and also the measure of its successful implementation. Furthermore, a critique of neoliberalism suggests that fun plays a key part in governing emotions. Many teachers and practicum students describe "cleaning up" emotions and removing children from situations that might make them unhappy. For example, they may avoid speaking with children about death (even if children bring up the subject). As another example, it is rare to encounter a situation where children are invited to collaboratively give their opinions about a specific child's idea or work for fear that the child might be upset by such interactions. Many times I have witnessed adults intervening in children's conflicts. We have moved away from allowing ambivalence in children's emotional lives or supporting ways of being that are more complex than being happy. This is important to pinpoint because it implicates lifestyles and practices valorized in what Ahmed (2010) calls the "happiness turn" (p. 2) and by 
which, I argue, neoliberalism in its recent incarnations forms the basis for subjective and collective well-being. Such lifestyles are characterized by naturalized and uncontestable "micropractices of self government, understood as intimate and personal enterprises" (Binkley, 2011, p. 372). Well beyond the apparently personal matters they involve, these micro practices prescribe less and more valuable ways of being in the world. Further, they demarcate what becomes impossible to think within a collective. I will come back to this point later.

\section{Who is the Educator Allowed to be in a Pedagogy of Fun?}

If fun as a discourse not only characterizes our experiences but prescribes a particular subjectivity, then one can ask: Who is the educator allowed to be in a pedagogy of fun? In a pedagogy of fun, the educator is an entertainer and impresario, a facilitator of fun experiences. The educator in such pedagogy calculates the benefits and satisfaction of experiences, both of which, according to Brown (2003), are calculations and conduct typical of an entrepreneurial actor. Within such calculations, the educator becomes an editor of knowledge and culture in a way that can avoid processes of meaning and thinking that could be classified as "boring" or difficult.

And what of the child? The child is positioned as nothing more than a consumer of experiences as they are presented to her or him. This denigration allows for the smooth deposition of the image of the child as what legitimates the teacher's competence in a prevalent discourse, as a mere postulate of "excellence" in education.

In the pedagogy of fun, the pedagogical relationship between teachers and children is based on a teacher's desire to engage children in entertainment and the children's expectations of the same. The teacher is there to guarantee fun experiences, and the child is there to judge them as such. One of the main characteristics of the pedagogy of fun is an apparent learning process that is clear, simple, quick, recognizable, and "easy to take."

The reduction of pedagogical complexity to a manageable minimum is the most convenient attribute of a neoliberal educational milieu. iii A pedagogy of fun tends to reduce and distort the complexity of life to fit into a simplistic (and concrete - which is to say consensual) mode of understanding the world; life is, in other words, wholly "appropriate." One surely, therefore, may classify as "boring" or "not fun" experiences that involve difficulty, disorientation, unfamiliarity, trouble, struggle. Appealing to a consensual presupposition, pedagogies of fun allow us to prescribe quick, short processes that lead to clear, concrete, and easily understandable answers (which are, of course, predictable and measurable). More complex ways of creating meaning and relating to the world are to be avoided. Indeed — such is neoliberal morality — they are "not appropriate." 
Children therefore may be caught up in processes that even their teachers do not recognize so much as unwittingly impose. Ways of thinking about the world evidenced by pedagogies of fun are intimate with what I have called elsewhere a "capricious anti-intellectualism symptomatic of a market culture" (Vintimilla, 2012, p. 15) and are supported by a reduction of school to a "skill and knowledge factory (or corporation)" (Pinar, 2011,p. 8) and by the "standardized test-making industry" (Pinar, 2011, p. 8) of neoliberal audit culture.

\section{Happy Tales and Their Politics of Niceness}

More broadly considered, the status quo discussed above is one of silent subjectivities, cultural conformity, and the pervasive symptoms of political apathy. For the neoliberal subject, the limit of one's responsibility is care for one's self; it does not extend to care for the public. As Wendy Brown (2003) writes:

The model neo-liberal citizen is one who strategizes for her/himself among various social, political and economic options, not one who strives with others to alter or organize these options. A fully realized neo-liberal citizenry would be the opposite of public-minded; indeed, it would barely exist as a public. (p. 43)

In my experience, the political apathy and the model neoliberal citizen Brown describes are frequently seen in early childhood contexts. I would argue that certain stereotypes and cultural myths - particularly those about community and teacher identity - make available discursive practices that help sustain the neoliberal subjectivities Brown describes. For example, in conversations with educators, I often notice that the coming together of the educational collective (of schools' culture) takes place within a politics of niceness, one characterized by a commitment to social harmony, to a common good. This commitment prescribes the privileging of certain ways of being - of certain feelings, responses, and actions - and the denigration and dismissal of others. Such a politics (of niceness) expresses a profound concern for the personal and the superficially affective, thus prescribing the ways a collective exists in these contexts as if the well-being of such a collective is defined by the warmth of its relations and its commitment to harmony. A certain etiquette of niceness prevails, one that functions as a social code and substantiates the neoliberal "happiness turn" introduced above.

This politics of niceness (which presupposes the unity of community rather than the diversity of difference) is reinforced by a generalized conception of early childhood educators (most of them female) first and foremost as care providers and protectors. Both of these roles are synonymous with domestic nurturers and guarantors of familial harmony. These myths, of course, sustain a broader image of who a woman is within our patriarchal society, and they also emerge from this conception (see Grumet, 1998). We find antecedents of this conception in the traditional feminine notion of "niceness," of the timid female virtue so alive and well in the gender ghetto 
that remains in early childhood education in many societies, including North America. Here, I am referring to the professional identity that commonly populates the imaginaries of who an early childhood educator is - the "Lady Bountiful" teacher (Harper \& Cavanaugh, 1994) — who is most often female, gracious, nurturing, loving, and ready to inculcate children with a particular set of social and moral norms (see Langford, 2007; Meiners, 2002). Women "do" early childhood education, and thus traditional "female" virtues continue to find fertile ground in these practices. These virtues and the characteristics of the nice teacher or Lady Bountiful are so normalized and naturalized in early childhood settings that they are often not considered problematic or even noticed. The "good early childhood educator," Langford (2007) writes, "is viewed as common sense and natural. Indeed, the particularity of the good early childhood educator is not heard by or visible to the listener, speaker, reader, or writer without considerable reflexivity" (p. 348), but such reflexivity might not be welcome in pedagogical contexts governed by a politics of niceness.

Within such discourses is the intimate connection between these "harmonizing" approaches and the political apathy or conformism that keeps alive the neoliberal status quo and allows it to remain unthought. This is a status quo that can infuse teaching with a gross lack of intellectual curiosity, where thinking is marginalized as auxiliary, or even held in a sort of fearful contempt because of its disruptive invitation of doubts, questions, uncertainties, and impasses. All these conditions have come to be held as anathema to professionalism in early childhood education. More broadly, they are taken as signs of not knowing how to live well. This, I submit, is because of the risk that they might provoke conflict and separation and unsettle an always precarious collective harmony. Thus, often there seems to be a need to eradicate these conditions from our relations with others, to order them, in some vague sense, to a presumed (good) world.

\section{An Invitation for New Thinking}

As experience is denigrated by a pedagogy of fun and apathetic neoliberal subjectivities are allowed to predominate in their happiness curricula, vital socio-political culture is likewise denuded by the smiling normalization of the virtue of niceness. None of this is to argue for the opposite: that we should be brutish to each other. It is rather to pursue this paper's invitation to outline the implications of neoliberalism in early childhood education and indicate how early childhood education serves the neoliberal project by maintaining the status quo through a sort of political apathy that is symptomatic of the diminishing criticality caused by a pedagogy of fun and a politics of niceness. I bring this discussion forward as a way to open windows into our field to allow the fresh air of new thinking, awkward as doing so always is at first. It is a risk we have to take if we wish to avoid allowing risk aversion to become the virtue that neoliberalism seems to propose. It is a risk we have to take if we are to be educators - that is, teachers nourished by the complexity of our times, inspired by the richness of the unending challenge of our work, but also educators who refuse to be constrained and directed by the promise of a pedagogy of fun and its resulting condition of a passive and impoverished conception of happiness. 


\section{Acknowledgements}

Thank you to Graham Giles for his important and helpful feedback and to Dr. Linda Farr Darling for her insight.

\section{References}

Ahmed, S. (2006). Queer phenomenology: Orientations, objects, others. Durham, NC: Duke University Press.

Ahmed, S. (2010). The promise of happiness. Durham, NC: Duke University Press.

Binkley, S. (2011). Happiness, positive psychology, and the program of neoliberal governmentality. Subjectivities, 4, 371-394.

Brown, W. (2003). Neo-liberalism and the end of liberal democracy. Theory \& Event, 7(1). Retrieved from: http://muse.jhu.edu/login?auth=0\&type=summary\&url=/journals/tae/v007/7.1brown.$h t m l$

Bryant, C., \& Forsyth, C. (2005). The fun god: Sports, recreation, leisure, and amusement in the United States. Sociological Spectrum, 25, 197-211.

Cook, D. (2004). The commodification of childhood: Personhood, the children's wear industry, and the rise of the child-consumer, 1917-1962. Durham, NC: Duke University Press.

Foucault, M. (1994). The subject and power. In J. Faubion (Ed.), Michel Foucault: Power. New York, NY: New Press.

Grumet, M. (1988). Bitter milk: Women and teaching. Amherst, MA: University of Massachusetts.

Harper, H., \& Cavanaugh, S. (1994). Lady Bountiful: The white woman teacher in multicultural education. Women's Education, 11(2), 27-33.

Kant, I. (1979). The conflict of the faculties. M.J. Gregor (Trans.). New York, NY: Abaris Books. (Original work published 1798)

Langford, R. (2007). Who is a good early childhood educator? A critical study of differences within a universal professional identity in early childhood education preparation programs. Journal of Early Childhood Teacher Education, 28(4), 333-352.

Meiners, E. (2002). Disengaging from the legacy of Lady Bountiful in teacher education classrooms. Gender and Education, 14(1), 85-94.

Nussbaum, M. C. (2010). Not for profit: Why democracy needs the humanities. Princeton, NJ: Princeton University Press. 
Pinar, W. (2011). Allegories of the present: Curriculum development in a culture of narcissism and presentism. Paper presented as part of the Pinar Seminar Series 2011-2012, University of British Columbia, Vancouver, Canada.

Vintimilla, D.C. (2012). Aporetic openings in living well with others: The teacher as a thinking subject. Unpublished doctoral dissertation. University of British Columbia, Vancouver, Canada. Retrieved from:

https://circle.ubc.ca/bitstream/handle/2429/42557/ubc_2012_fall_delgadovintimilla_mariacristina.pdf ?sequence $=5$

\section{Endnotes}

${ }^{\mathrm{i}}$ By managing subjectivities I am referring to a set of daily practices and discourses that, in a selfevident, taken-for-granted way, are assumed to be the appropriate way of being, thus they regulate and normalize subjects' collective lives.

${ }^{\text {ii }}$ In another paper it might be worthwhile to ask questions regarding fun as a technology to manage subjectivities in relation to the ones who do not participate in such discourses of fun. I am thinking about individuals who might be labelled as the "difficult" ones, the "troublemakers," the "strange" or otherwise aberrant ones.

iii Although is not within the scope of the present article, it is worthwhile noticing here the profound material connection between the process that such a pedagogy of fun fosters and the overwhelming presence of commodities or products in pedagogical contexts. These commodities are defined as "beneficial goods" (Cook, p. 5) for children because they foster fun or so-called educational moments. This connection is symptomatic of learning contexts and children in which both are already embedded historically in the market cultures of late capitalism. These cultures are becoming ever more consumer-driven places inhabited by consumer-driven subjects. 


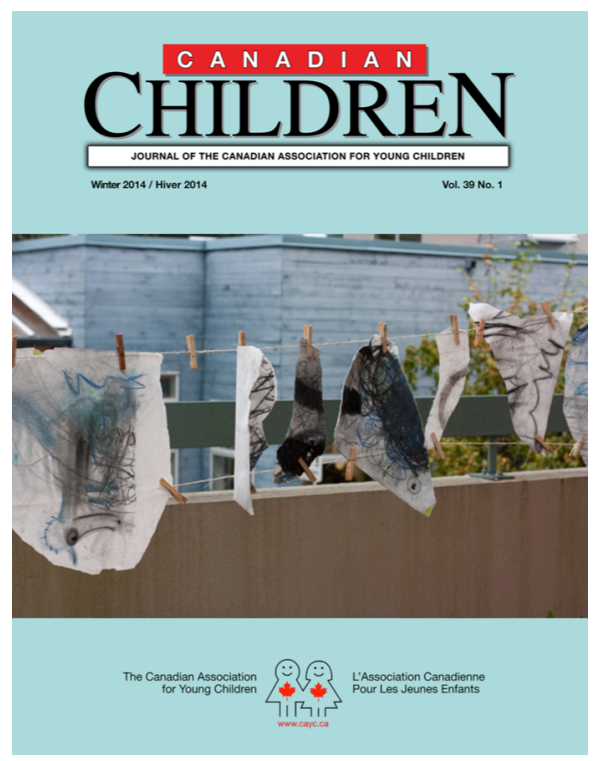

\section{In this issue:}

From the Editor's Desk

Special Issue: Neoliberalism

Guest Editor Dr. Luigi Iannacci, PhD, Trent University,

Peterborough, Ontario

I've got my EYE on you:

Schooled Readiness, Standardized Testing, and Developmental Surveillance

by Emily Ashton

Bear-Child Stories in Late Liberal Colonialist Spaces of Childhood by Veronica Pacini-Ketchabaw, Lara di Tomasso, Fikile Nxumalo

Producing Neoliberal Parenting Subjectivities:

ANT-Inspired Readings from an Informal Early Learning Program by Rosamund Stooke

Neoliberal Fun and Happiness in Early Childhood Education

by Cristina D. Vintimilla

Radical Education and the Common School:

A Democratic Alternative

by Michael Fielding and Peter Moss

Reviewed by Kim Atkinson

Call for Contributions:

'The Visual Arts in Early Childhood Education'

Find other articles from this issue at www.cayc.ca 